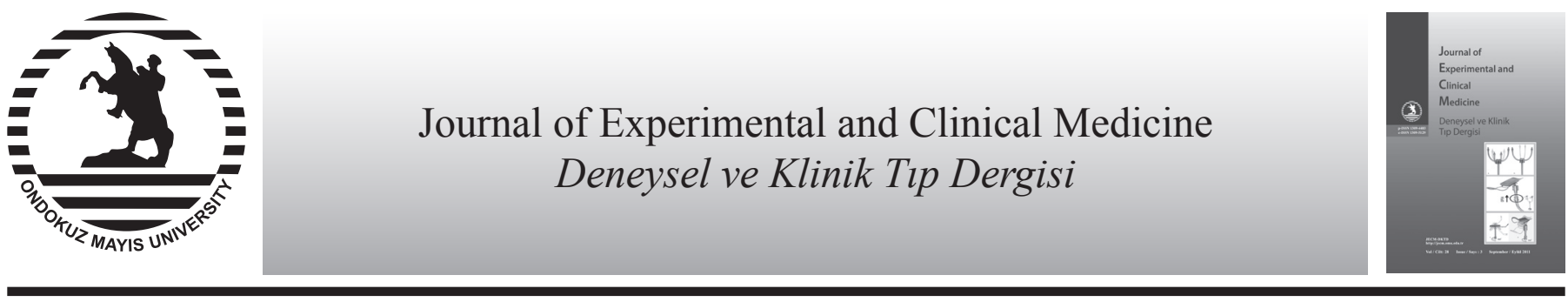

Case Report

doi: $10.5835 /$ jecm.omu.28.03.004

\title{
Recurrent abortions and postnatal loses in two cases including G-negative band within Chromosome 1qh region
}

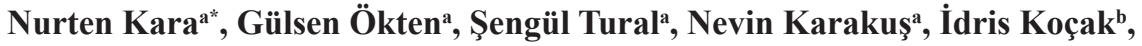 \\ ${ }^{a}$ Department of Medical Biology and Genetics, Ondokuz Mayis University, Faculty of Medicine, Samsun, Turkey \\ ${ }^{b}$ Department of Gynecology and Obstetrics, Ondokuz Mayis University, Faculty of Medicine, Samsun, Turkey
}

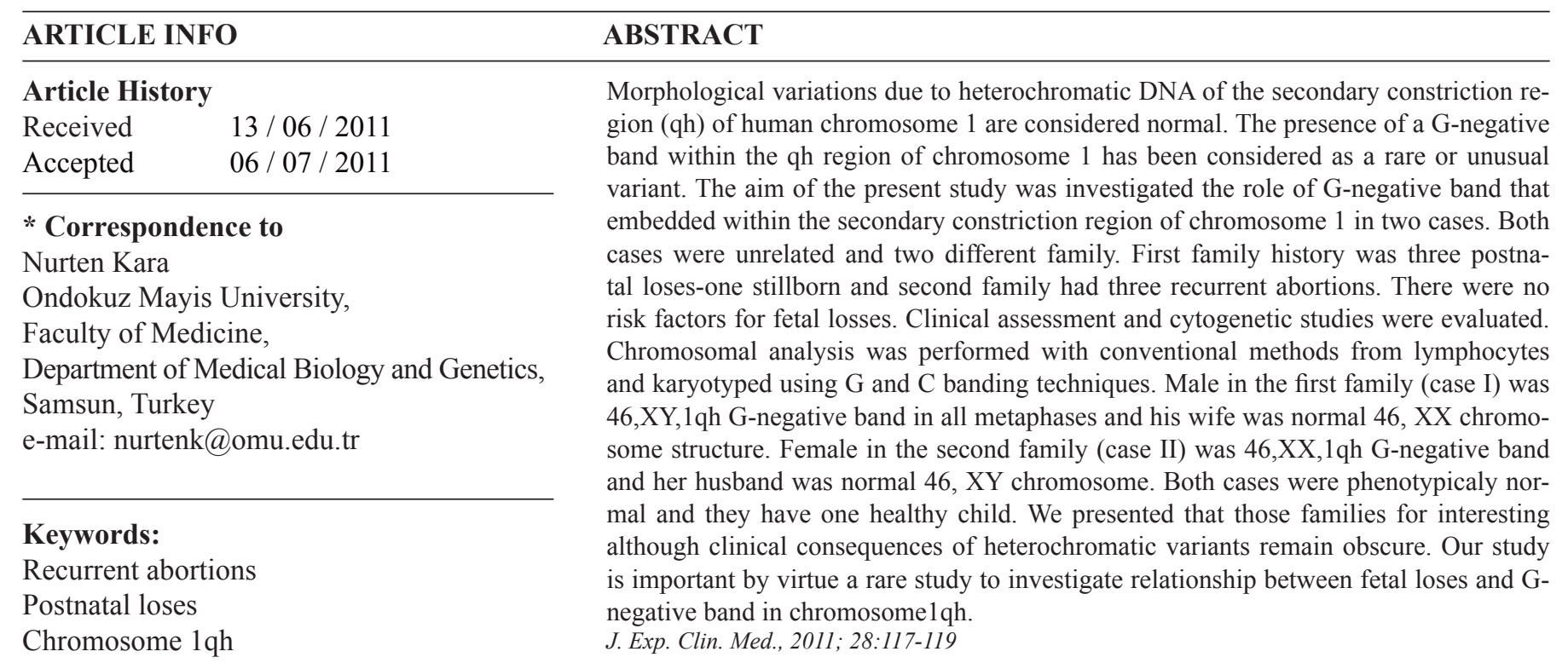

G-negative band

Fetal losses

Cytagenetic studies

C 2011 OMU All rights reserved

\section{Introduction}

The heterochromatic segments on the long arms of chromosomes 1, 9 and 16 have been defined as secondary constriction (qh) regions (Verma, 1988). Heterochromatin confined to the qh region has, through some unknown mechanisms, a strong affinity for pericentric inversion (Verma et al., 1984, Luke et al., 1992). The variation of chromosomes with qh have been classified into two classes, termed "size" and "inversion" heteromorphisms (Verma et al., 1978). A third type of variation has surfaced wherein an additional G-positive or G-negative bands is sandwiched within the qh region of chromosome 9 and 1 (Macera et al., 1995; Verma et al., 1997). If Giemsa is used, the dark band is called G-band or G-positive band, and the light band is named G-negative band. We were referred two cases where a G-negative band was embedded within the secondary constriction region of Chromosome 1.

\section{Cases}

Case 1

A 41-years- old male and his wife 39-years old female whose three postnatal loses (two girls and one boy) and one still- born (boy) were referred for chromosome analysis by gynecology clinics. They have a healthy son in seven years-old. His mothers have three postnatal loses. His father was died (Fig. 1).

\section{Case 2}

A 31-years old woman and her husband 32-years old male whose three recurrent abortions were referred for chromosome analysis by gynecology clinics. They have a healthy girl in six years-old (Fig. 2). Their parents were not any problem. Both of cases were unrelated whose histories three postnatal loses-one stillborn and three recurrent aborts respectively.

Both cases and their parents' peripheral blood lymphocytes were cultured following a standard protocol. GTG-, CBG-banding techniques performed as previously described (Verma and Babu, 1995). At least 20 metaphases were analyzed in each case and them relations and visualized to image analyzer (PCI Scientific System).

\section{Results}

Case 1 and his wife were phenotypicaly normal. There were no risk factors for fetal losses. The examination of them re- 
vealed 46,XY,1qh G-negative band and 46,XX, respectively. Case I had a G-light (negative) band that was embedded

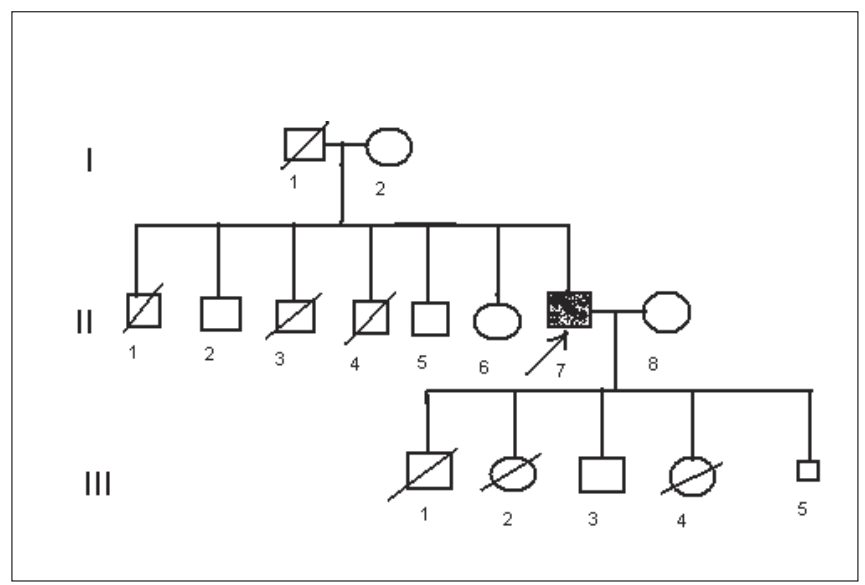

Fig. 1. Pedigree of case I.

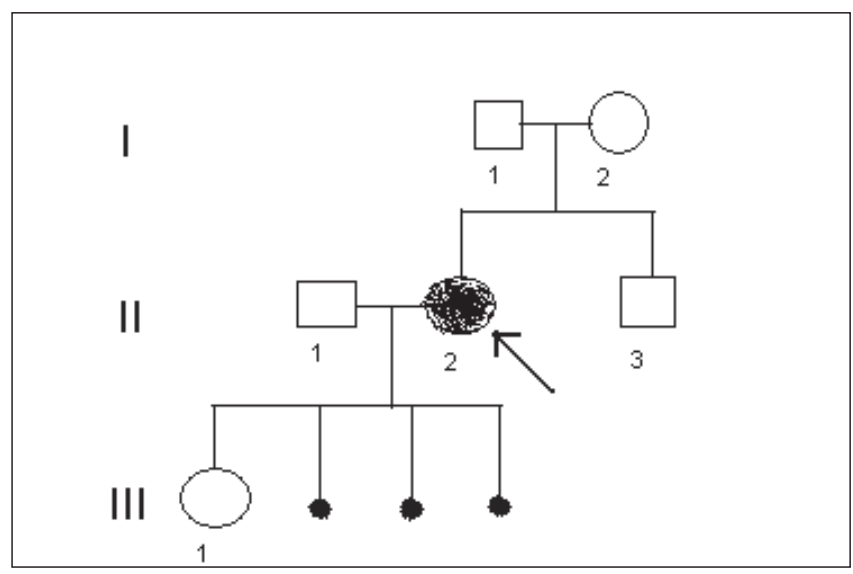

Fig. 2. Pedigree of case II.

within the secondary constriction region of Chromosome 1 (Fig. 3a).

All other chromosomes were normal. His mother and son was not chromosome 1qh G-negative band. His mother was three postnatal loses and one girl and three sons with healthy but his father was not investigated for died (Fig. 1).

The second case and her husband were phenotypicaly normal. Also they were no risk factors for fetal losses. On cytogenetic examination, she (Case 2) had chromosome structure that including 46,XY,1qh G-negative band (Fig. 3a,b). Her husband was cytogenetically normal. All other chromosomes were normal. Her daughter, mother, and father had normal chromosomes (Fig. 2). On analysis CBG band, both cases were shown an extra euchromatic band within 1qh region. (Fig. 4a, 4b).

\section{Discussion}

The euchromatic band sandwiched within the heterochromatic blocks might have been inactivated (Verma et al., 1993).
The presence of extra G-band may suppress the synaptonemal complex formation and crossing-over in the qh region (Ashley, 1988) and this chromosome can be passed on to the next generation, without any consequences.

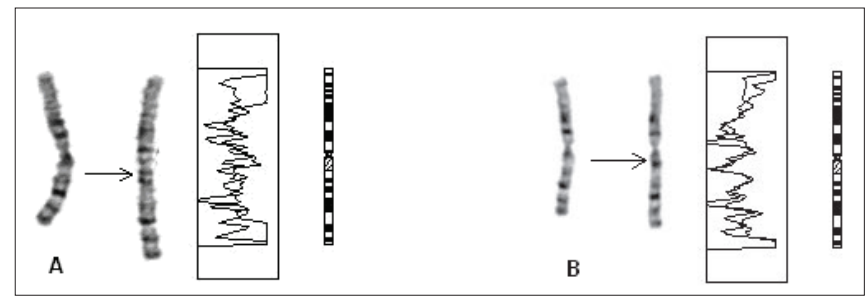

Fig. 3. GTG banding pattern of chromosome 1 in case I (a) and case II (b). G-negative band embedded within 1qh region (arrow) while normal qh region is shown on left.

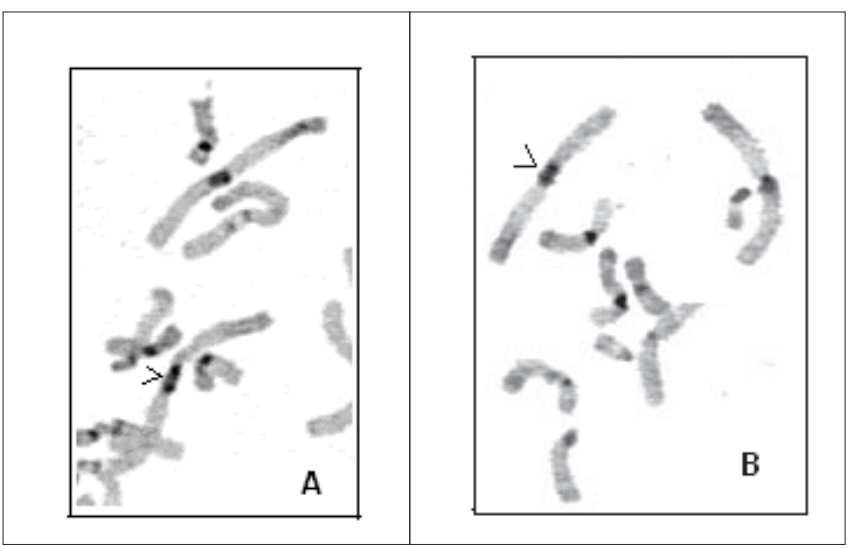

Fig. 4. CBG banding pattern of chromosome 1; in the case I (a) and case II (b). The extra euchromatic band within 1qh region (arrow).

We reported that recurrent abortions and postnatal loses in two cases including G-negative band within chromosome 1qh region. Imai et al., (1995) suggested that the recurrent abortion associated with 1qh+. However, associate with 1qh variations of the postnatal loses was not found in the literature as our case.

Chromosomal variations have an important role in genomic evolution (Bernardi and Bernardi, 1986). Occasionally, regulator genes can be embedded within the "junk DNA" which may be act as a silencer (Macera et al., 1995). Heterochromatin has been regarded as a meaningless region in the genome. This region could alter to functions certain genes surround.

\section{Acknowledgements}

This study was published as a poster paper in Mediterrenean Medical Genetics Congress, June 28- July 1, 2009 Bilkent, Ankara.

\section{REFERENCES}

Ashley, T., 1988. G-band position effects on meiotic synapses and crossing over. Genetics, 118, 307-317.

Bernardi, G., Bernardi, G., 1986. Compositional constraints and genomic evolution. J. Molec. Evol. 24, 1-11.

Imai, A., Misao, R., Tamaya, T., 1995. Recurrent abortion associated with 1qh+. J. Med. 26, 343-345.

Knight, L.A., Soon, G.M., Tan, M., 1993. Extra G positive band on the long arm of chromosome 9. J. Med. Genet. $30,613$.

Luke, S., Verma, R.S., Conte, R.A., Mathews, T., 1992. Molecular characterization of secondary constriction region (qh) of human chromosome 9 with pericentric inversion. J. Cell. Sci. 103, 919-923. 
Macera, M.J., Verma, R.S., Conte, R.A., Bialer, M.G., Klein, V.R., 1995. Mechanisms of the origin of a G-positive band within the secondary constriction region of human chromosome 9. Cytogenet. Cell. Genet. 69, 235-239.

Ramesh, K.H., Verma, R.S., 1996. Breakpoints in $\alpha, \beta$, and satellite III DNA sequences of chromosome 9 result in a variety of pericentric inversions. J. Med. Genet. 33, 395-398.

Verma, R.S., 1988. Heterochromatin: molecular and structural aspects. Cambridge University Press, New York.

Verma, R.S., Babu, A., 1995. Human Chromosomes, Principles and Techniques, Second Edition, P:72-79, McGraw-Hill, Inc. USU.

Verma, R.S., Dosik, H., Lubs, H.A., 1978. Size and pericentric inversion heteromorphisms of secondary constriction region (h) of chromosomes 1, 9, and 16 as detected by CBG technique in Caucasians: classification, frequencies and incidence. Am. J. Med. Genet. 2, 331-339.

Verma, R.S., Luke, S., Brennan, J.P., Mathews, T., Conte, R.A., Macera, M.J., 1993. Molecular topography of the secondary constriction region (qh) of human chromosome 9 with an unusual euchromatic band. Am. J. Hum. Genet. 52, 981-986.

Verma, R.S., Kleyman, S.M., Conte RA., 1997. An unusual G- negative band within 1qh region a rare variant or an abnormality? Ann. Genet. 40, 229-231.

Verma, R.S., Rodriguez, J., Shah, J.V., Dosik, H., 1984. Chromatin of h-region of human chromosomes at high resolution. Experientia. 40, 878879. 